\title{
Application of solar maps to select a rational shape of the shading device for the tractor cabin
}

\author{
Viktor Maslensky ${ }^{1}$, Yuriy Bulygin ${ }^{1, *}$, Alan Temirkanov ${ }^{1}$, Ekaterina Shchekina $^{1}$, and Inna \\ Loskutnikova $^{1}$ \\ ${ }^{1}$ Don State Technical University, 344003, Gagarin sq., 1, Rostov-on-Don, Russia
}

\begin{abstract}
The article is devoted to the use of solar maps to determine the period of unwanted insolation and the amount of thermal radiation that penetrates into the tractor cabin throughout the entire working day. In addition, an optimal form of a sun-protection device has been proposed, which makes it possible to reduce the magnitude of the exposure dose of thermal radiation affecting the operator. Since solar radiation makes the main contribution to the heat balance of the cabins of mobile machines (tractors, combines, etc.), the results obtained can mainly be used in assessing the working conditions of operators and in calculating and choosing systems for normalizing the microclimate (ventilation and air conditioning).
\end{abstract}

\section{Introduction}

Solar radiation - electromagnetic oscillations with non-uniform wavelengths. The composition of solar radiation includes ultraviolet radiation with a wavelength of 290 to $400 \mathrm{~nm}$, visible - from 400 to $760 \mathrm{~nm}$ and infrared - from 760 to $2800 \mathrm{~nm}$. Ultraviolet radiation, due to its low content in the solar spectrum (1\%), has a generally positive effect on the human body. Infrared radiation (59\%), on the contrary, with prolonged exposure causes a negative effect - sunstroke. Quite often, such situations can be observed in natural conditions when working in confined spaces, located in direct sunlight, for example, when operating mobile agricultural machinery (tractors, combines, etc.). This fact is the reason for the increased requirements for the designed sun protection products [1].

To protect the operator's workplaces from the harmful effects of solar radiation, the design of mobile agricultural machines provides various protective equipment, in particular canopies that prevent sunlight from entering the cabin. This is achieved by creating a shaded area at the operator's workstation for a specified period of time during which exposure to sunlight is minimized [2-5].

The aim of the study is to evaluate the effectiveness of the sun protection device of the tractor cabin by determining the period of maximum overheating and the amount of solar radiation penetrating into the cabin.

Tasks:

*Corresponding author: bulyur_rostov@mail.ru 
1) Build the shadow mask of the tractor cabin visor on the solar map.

2) Determine the period of maximum overheating and the amount of solar radiation and compare with the standard values.

3) Suggest the optimal shape of the visor of the tractor cabin.

\section{Problem statement}

The object of the study was the MTZ-80 tractor, the cabin of which has a total glazing area of about $35 \%$. The geometric dimensions of the light openings of the tractor cabin are shown in Figure 1.
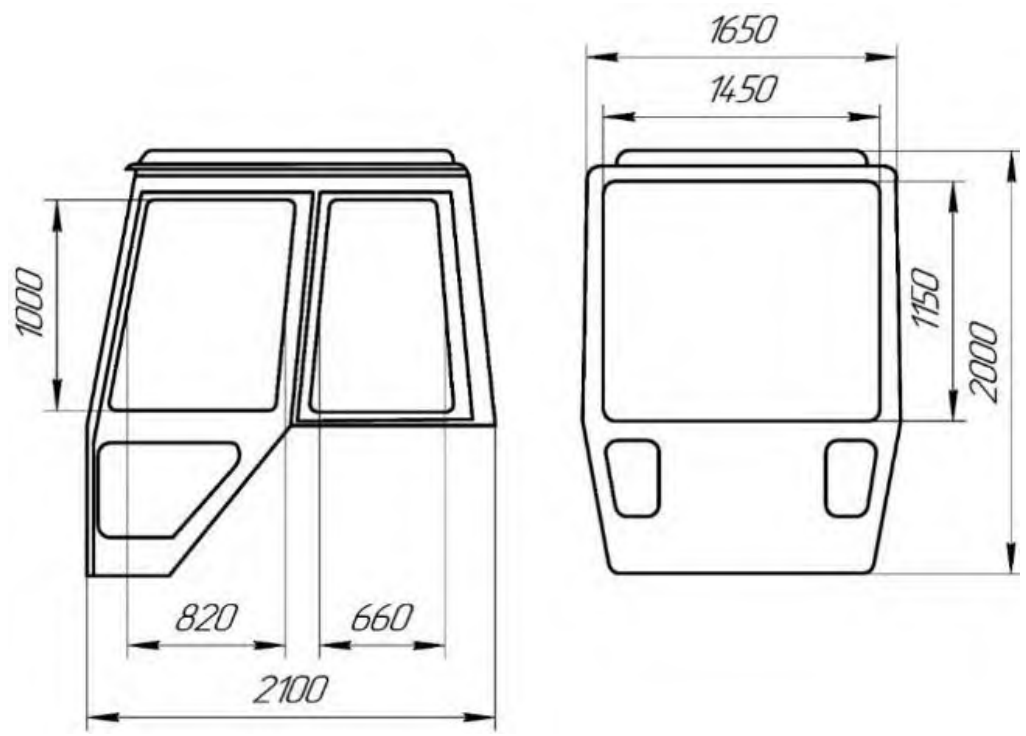

Fig. 1. The geometric dimensions of the light openings of the tractor cabin

The horizontal visor of the front light opening, the dimensions of which are $0.2 \times 1.45$ $\mathrm{m}$, is the basic element of shading the tractor cabin. The filling of the light opening is represented by standard clear glass $6 \mathrm{~mm}$ thick $[6,7]$. The method of constructing solar maps, which is a graphical tool for designing sun protection devices and determining the period of insolation, was chosen to study the effect of solar radiation on the tractor cabin. The solar map displays the trajectories of the sun across the sky and solar hour lines overlaid with the shadow mask of the sun protection device.

A shadow mask is a graphical representation on a solar map of the area of shading of the sky with sun protection devices (mainly visors). The shadow mask of the horizontal visor of the tractor cabin is shown in Figure 2. 

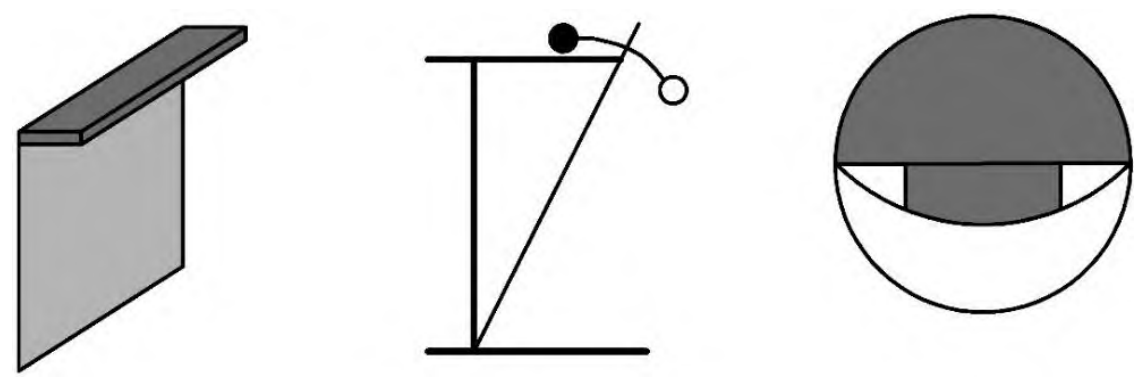

Fig. 2. Scheme of the horizontal visor of the tractor cabin and its shadow mask

\section{Theoretical part}

To assess the effectiveness of the horizontal visor of the tractor cabin, it is necessary that its shadow mask overlaps the overheating area on the solar map for the maximum number of hours (Figure 3).

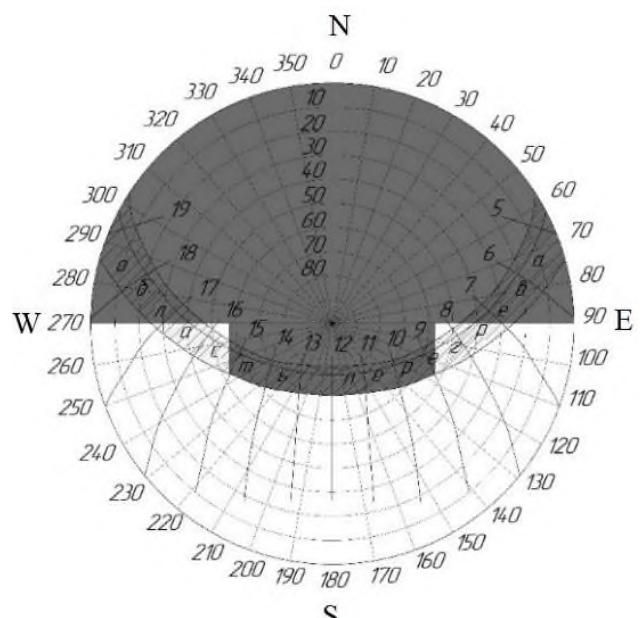

$\mathrm{S}$

Fig. 3. The shadow mask of the horizontal visor of the tractor cabin on the solar map

As seen from Fig. 3, the shadow mask of the horizontal visor of the tractor cabin covers most of the overheating area on the solar map, except for the time from 7 to 9 a.m. and from 3 to 5 p.m. Thus, the tractor cabin will receive $999 \mathrm{~W} / \mathrm{m} 2$ of direct solar radiation and 251 of scattered solar radiation from the east side and from the west side $-114 \mathrm{~W} / \mathrm{m} 2$ of scattered solar radiation (Figure 4). The total solar radiation reaching the tractor cabin is $1364 \mathrm{~W} / \mathrm{m} 2$ [8-9]. 

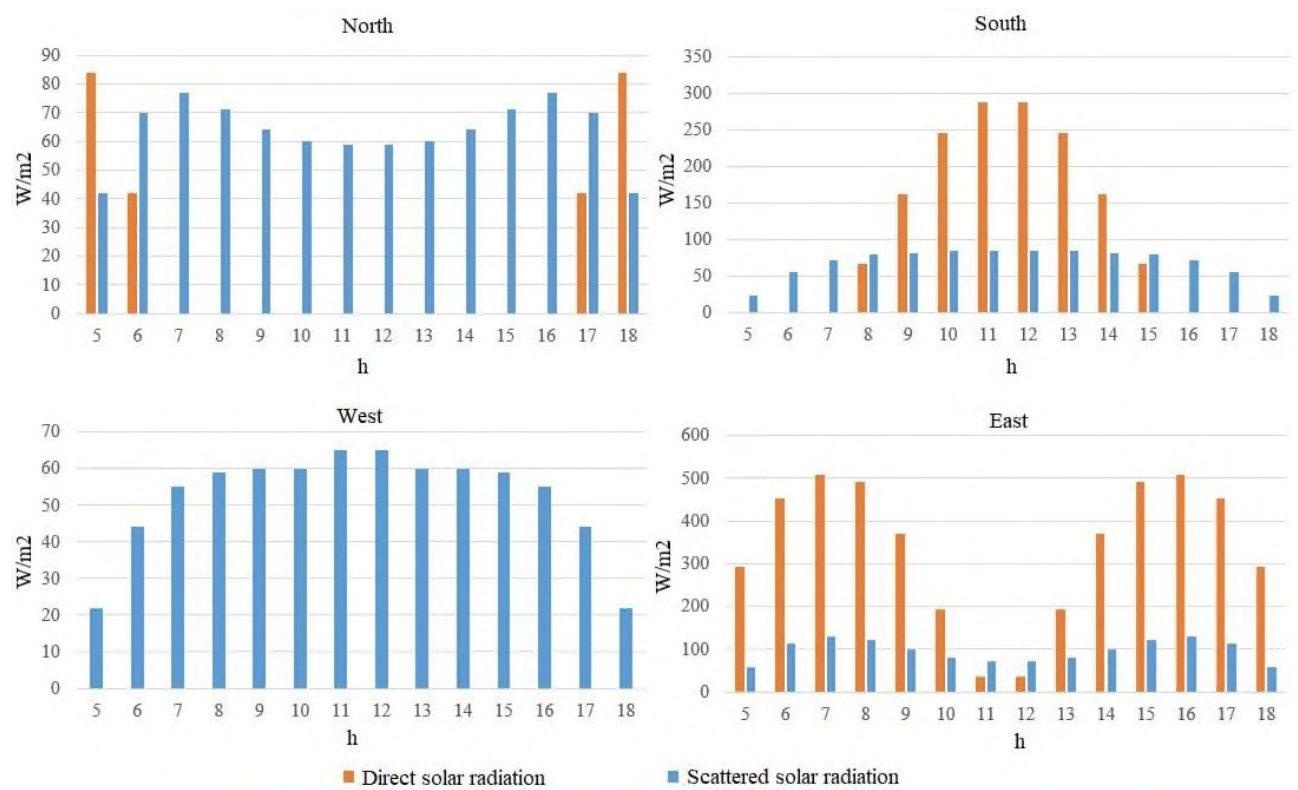

Fig. 4. Solar radiation in July at latitude of $47^{\circ}$ (Rostov-on-Don) 2:

Heat gain into the tractor cabin from solar radiation through the light opening $Q_{s}, W / m$

$$
\mathrm{Q}_{\mathrm{s}}=\mathrm{G} \cdot \mathrm{g} \cdot \mathrm{m} \cdot \tau
$$

where $\mathrm{G}$ - solar radiation entering the tractor cabin, $\mathrm{W} / \mathrm{m} 2 ; \mathrm{g}$ - colorless glass solar factor; $\mathrm{m}$ - the ratio of the glazing area to the area of the light opening; $\tau$ - shading coefficient of the sun protection devices (visor) [10-12].

$$
\mathrm{Q}_{\mathrm{s}}=1364 \cdot 0,8 \cdot 0,88 \cdot 0,95=912 .
$$

Knowing the magnitude of the heat inflow into the tractor cabin from the solar radiation, it is possible to determine the exposure dose of thermal radiation on the operator, $\mathrm{W} \cdot \mathrm{h}$ :

$$
\mathrm{DEO}=\mathrm{Q}_{\mathrm{s}} \cdot \mathrm{S} \cdot \mathrm{t}
$$

where $\mathrm{S}$ - area of body surfaces exposed to radiation, $\mathrm{m} 2 ; \mathrm{t}$ - duration of exposure, $\mathrm{h}$.

$$
\text { DEO }=912 \cdot 0,87 \cdot 4=3174 .
$$

To check the energy efficiency of the shading element of the tractor cabin let us compare the value of the exposure dose of the operator's thermal radiation with the hygienic standards used in the hygienic assessment of the classes of working conditions in terms of microclimate indicators (Table 1).

Table 1. Evaluation of the energy efficiency of the shading element of the tractor cabin

\begin{tabular}{|c|c|c|c|c|c|c|c|}
\hline \multirow{3}{*}{ Index } & \multicolumn{7}{|c|}{ Energy efficiency, \% } \\
\cline { 2 - 8 } & maximum & average & \multicolumn{4}{c|}{ low } & extremely low \\
\cline { 2 - 8 } & $\mathbf{8 5}$ & $\mathbf{7 5}$ & $\mathbf{6 5}$ & $\mathbf{5 5}$ & $\mathbf{4 5}$ & $\mathbf{3 5}$ & $<\mathbf{3 5}$ \\
\hline DEO, W·h & $<500$ & 500 & 1500 & 2600 & 3800 & 4800 & $>4800$ \\
\hline
\end{tabular}


The results of calculating the exposure dose of thermal irradiation of the tractor operator indicate, in general, the low energy efficiency of the horizontal shading element (45\%). As measures to reduce solar radiation, it is proposed to use a sunscreen of a different form, or glasses with a low solar factor. In this case, the vertical visor of the side light openings will be more effective, the diagram and the shadow mask on the solar map of which are shown in Figure 5. The filling of the light openings will be $6 \mathrm{~mm}$ thick green glass with improved light and heat shielding properties.
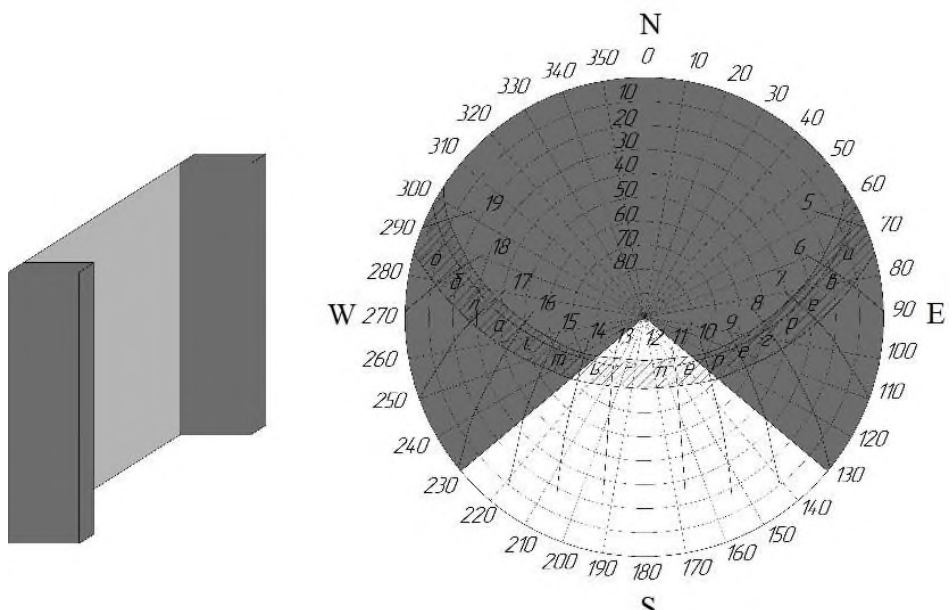

Fig 5. Outline and shadow mask of the vertical visor of the tractor cabin on the solar map

According to Figure 5, the shadow mask of the vertical visor of the tractor cabin covers most of the overheating area on the solar map, except for the time interval from 11:00 a.m. to 2:00 p.m. Thus, the tractor cabin will receive $821 \mathrm{~W} / \mathrm{m} 2$ of direct solar radiation and 254 $\mathrm{W} / \mathrm{m} 2$ of scattered solar radiation from the south side (Figure 4). The total solar radiation reaching the tractor cabin $1075 \mathrm{~W} / \mathrm{m} 2$.

Heat gain into the tractor cain from solar radiation through the light opening filled with green glass, which has a lower solar factor in comparison with clear glass, Qs, W/m2:

$$
\mathrm{Q}_{\mathrm{s}}=1075 \cdot 0,46 \cdot 0,88 \cdot 0,95=413 \text {. }
$$

Exposure dose of operator's thermal radiation DEO, W.h:

$$
\mathrm{DEO}=413 \cdot 0,87 \cdot 4=1437 .
$$

The results of calculating the exposure dose of thermal radiation of the tractor operator confirm the higher energy efficiency of the vertical shading element in combination with green glass $(65 \%)$ (Table 1). However, this value still exceeds the sanitary and hygienic standard of $500 \mathrm{~W} \cdot \mathrm{h}$. Therefore, we will achieve a decrease in the exposure dose of thermal radiation and achieve maximum energy efficiency by applying a vertical casing of side light openings located at an angle of $45^{\circ}$ to the plane of the tractor cabin, a diagram and a shadow mask of which is shown in Figure 6 . The filling of the light openings is $6 \mathrm{~mm}$ thick blue glass, which has slightly improved light and heat-shielding properties than green glass. 

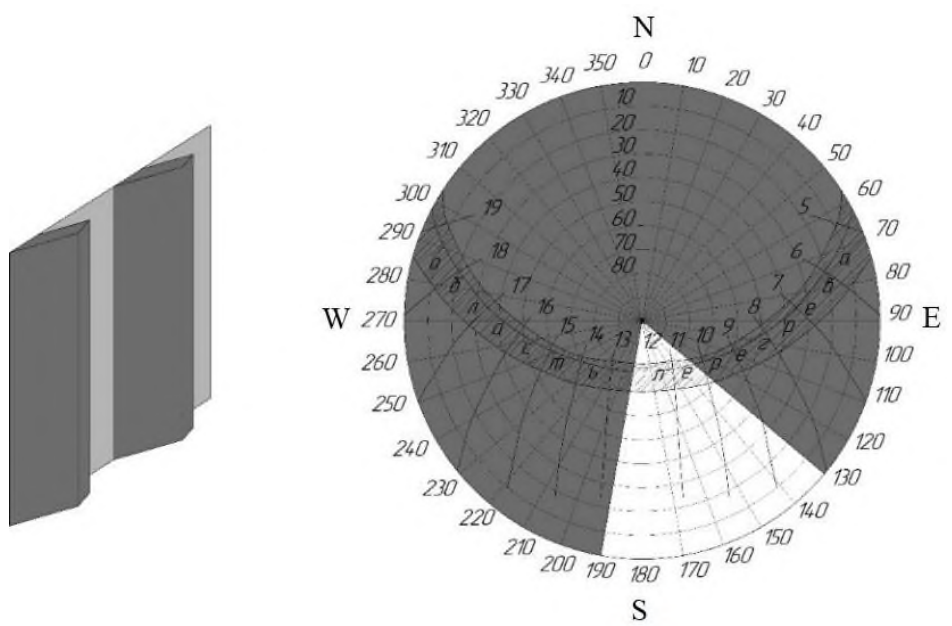

Fig. 6. Scheme and the shadow mask of a vertical visor of a tractor cabin on a solar map at the angle of $45^{\circ}$

According to Figure 6, the shadow mask of the vertical visor of the tractor cabin covers most of the overheating area on the solar map, except for the time interval from 10 to 12 . Thus, the tractor cabin will receive $576 \mathrm{~W} / \mathrm{m} 2$ of direct solar radiation and $170 \mathrm{~W} / \mathrm{m} 2$ of scattered solar radiation from the south side (Figure 4). The total solar radiation reaching the tractor cabin is $746 \mathrm{~W} / \mathrm{m} 2$.

Heat gain into the tractor cabin from solar radiation through a light opening filled with blue glass, which has a slightly lower solar factor compared to green glass, Qs, W/m2:

$$
\mathrm{Q}_{\mathrm{s}}=746 \cdot 0,45 \cdot 0,88 \cdot 0,95=281 .
$$

Exposure dose of DEO operator's thermal radiation, $\mathrm{W} \cdot \mathrm{h}$

$$
\mathrm{DEO}=281 \cdot 0,87 \cdot 2=489 .
$$

The results of calculating the exposure dose of thermal radiation of the tractor operator indicate the maximum energy efficiency of a vertical shading element located at an angle of $45^{\circ}$ in conjunction with blue glass (> $85 \%$ ) (Table 1). Moreover, the obtained value does not exceed the sanitary and hygienic standard [13-15].

\section{Discussion and conclusion}

The method of constructing solar maps made it possible to establish the duration of the adverse effect of solar radiation for the entire working day (4 hours), based on the available data on the shape of the horizontal shading device of the tractor cabin (visor) and its shadow mask.

According to the results of the subsequent calculation of the exposure dose of thermal radiation on the tractor operator, a low efficiency of the visor of the tractor cabin was revealed (60-35\%). At the same time, the value of the total heat flow into the cabin was $1364 \mathrm{~W} / \mathrm{m} 2$, which exceeds the sanitary and hygienic standard by 9.7 times. In this regard, it is proposed to use a vertical sun protection device, which will ensure compliance with the standard value of the influencing factor. 
As a result, the most optimal variant of the vertical visor of the tractor cabin, located at an angle of $45^{\circ}$, makes it possible to achieve an increase in the sun protection efficiency by $53 \%$ and the DEO value lower than the maximum permissible level.

Solar radiation makes the main contribution to the thermal balance of the cabins of mobile cars, therefore, its correct assessment is an important step in the calculation and selection of microclimate normalization systems, for example, a climate system. At the same time, the parameters of the selected climate system will provide a high degree of decrease in the air temperature inside the cabin, which will have a beneficial effect on the well-being of the operator.

\section{References}

1. H. Liang, et al, Energy, 158, 719-729 (2018) doi: 10.1016/j.energy.2018.06.059.

2. Q. Zhu, et al, Energy and Buildings, 206, 109584 (2020) doi: 10.1016/j.enbuild.2019.109584.

3. L. Evangelisti, et al, Journal of Building Engineering, 28, 101089 (2020) doi: 10.1016/j.jobe.2019.101089.

4. A. Kirimtat, et al, Renewable and Sustainable Energy Reviews, 53, 23-49 (2016) doi: 10.1016/j.rser.2015.08.020.

5. G. Kim, et al, Energy and Buildings, 46, 105-111 (2012) doi: 10.1016/j.enbuild.2011.10.040.

6. B. Ch. Meskhi, Yu. I. Bulygin, V. V. Maslensky, State and prospects for the development of the agro-industrial complex: collection of articles. scientific. tr. XII Int. scientific-practical conf., 653-657 (2019) doi: 10.23947/interagro.2019.9.653-657.

7. V. V. Maslensky, Yu. I. Bulygin, State and prospects for the development of the agroindustrial complex: anniversary collection. scientific. tr. XIII Int. scientific-practical conf., 28-31 (2020) doi: 10.23947/interagro.2020.2.28-31.

8. Y. I. Bulygin, et al, AIP Conference Proceedings, 2188, 050033 (2019) doi: $10.1063 / 1.5138460$

9. B. Meskhi, et al, IOP Conference Series: Earth and Environmental Science, 403, 012089 (2019) doi:10.1088/1755-1315/403/1/012089

10. K. Lai, et al, Solar Energy, 147, 113-125 (2017) doi: 10.1016/j.solener.2016.10.015.

11. D. L. Marinoski, et al, Building and Environment, 144, 72-85 (2018) doi: 10.1016/j.buildenv.2018.08.007

12. Y. Cascone, et al, Solar Energy, 85, 2524-2539 (2011) doi: 10.1016/j.solener.2011.07.011.

13. A. P. Saveliev, S. V. Glotov, S. A. Enaleeva, V. A. Vaskyanin, Science, technology and education, 6(47), 22-28 (2018)

14. S. A. Rodimtsev, A. I. Gavrichenko, I. V. Galyanov, R. P. Belikov, Bulletin of NGIEI, 12(79), 53-63 (2017)

15. A. I. Gavrichenko, R. P. Belikov, A. N. Shapovalov, Agricultural machinery and energy supply, 1(5), 125-130 (2015) 